\title{
Comparison of the Effects of Simultaneous Use of Methylergonovine and Combined Low-dose (LD) Contraceptive Pills on Hemorrhage Due to Retained Pregnancy Products after Abortion
}

\author{
Maasumeh Kaviani ${ }^{1}$, Tahere Abdullahi Tehrani ${ }^{2}$, Sara Azima $^{1 *}$, \\ Khadijeh Abdali ${ }^{1}$ and Nasrin Asadi ${ }^{3}$ \\ ${ }^{1}$ Department of Midwifery, School of Nursing and Midwifery, Shiraz University of \\ Medical Sciences, Shiraz, Iran \\ ${ }^{2}$ Student Research committee, Shiraz University of Medical Sciences, Shiraz, Iran \\ ${ }^{3}$ Department of Gynaecology and Obstetrics, School of Medicine, Shiraz University of \\ Medical Sciences, Shiraz, Iran \\ *Corresponding author
}

\begin{tabular}{ll}
\hline & A B S T R A C T \\
\cline { 2 - 3 } & $\begin{array}{l}\text { In some cases, bleeding persists after spontaneous abortion during the first trimester of } \\
\text { pregnancy, indicating incomplete expulsion of conception products. The present study } \\
\text { aimed to compare the effects of concomitant use of methylergonovine and combined } \\
\text { Low Dose (LD) contraceptive pills on prevention of hemorrhage and promotion of } \\
\text { complete expulsion of retained pregnancy products. In the present randomized clinical } \\
\text { trial, the subjects consisted of 111 women with a complaint of persistent hemorrhage } \\
\text { after spontaneous abortion, who had referred to the gynecology clinics of Shiraz }\end{array}$ \\
$\begin{array}{l}\text { Spontaneous } \\
\text { abortion, Oral } \\
\text { Combined }\end{array}$ & $\begin{array}{l}\text { University of Medical Sciences. The subjects were randomly divided into } 3 \text { groups of } \\
\text { Contraceptives, }\end{array}$ \\
$\begin{array}{l}\text { Methergine, } \\
\text { Hemorrhage. }\end{array}$ & $\begin{array}{l}\text { with combined LD contraceptive pills for 21 days, group } 2 \text { was given } \\
\text { methylergonovine pills alone, and group } 3 \text { had to use LD pills alone. The volume of } \\
\text { hemorrhage, number of days of hemorrhage and complete expulsion of conception } \\
\text { products were evaluated. The data were; however, LD pill resulted in a more } \\
\text { significant decrease in the number of days and volume of hemorrhage [P<0.0001]. In } \\
\text { addition, in all the three groups, the retained pregnancy products were analyzed using } \\
\text { the SPSS statistical software. All the three medication regimens resulted in the } \\
\text { expulsion of pregnancy products and a decrease in hemorrhage completely expelled } \\
\text { after completion of the course of treatment. In the present study, the combined LD } \\
\text { contraceptive pills were more effective in decreasing the number of days hemorrhage } \\
\text { persisted and the hemorrhage volume. }\end{array}$ \\
\hline $\begin{array}{l}\text { Accepted: } \\
\text { Available } \text { Online: } \\
\text { 10 November 2016 }\end{array}$ & \\
\hline
\end{tabular}

\section{Introduction}

Approximately 205 million pregnancies occur all over the world annually; however, only $30-50 \%$ of conceptions successfully survive the first trimester (Lohr et al., 2008; Gabbe et al., 2012).
Incomplete abortion refers to the expulsion of the bulk of conception products, in which some components of the fetus, placenta, or fetal membranes are retained (Griebel et al., 2005). The prevalence of retention of 
pregnancy products at the end of the first trimester has been reported to be $1-3 \%$ and decreasing this high prevalence rate is a global aim (Debby et al., 2006). Persistent hemorrhage after abortion indicates the retention of small pieces of trophoblasts and decidua, which survive for some time after the death of the fetus or its expulsion (Sang et al., 1994). In most cases, surgery and curettage appear to be inevitable for treatment of incomplete abortion, which is usually associated with some complications, including hemorrhage (Cunningham et al., 2010; Jahangir et al., 2005). On the other hand, such procedures are costly and require specialists and advanced surgical and anesthetic equipment and operating rooms which are not available everywhere (Sakhavat et al., 2004). One of the pharmaceutical techniques to control hemorrhage after abortion is the use of methylergonovine which contracts the blood vessels in the body and the uterus, decreasing loss of blood. Some studies have shown the beneficial effects of methylergonovine on prevention and treatment of hemorrhage after delivery or abortion (Esmaelizadeh et al., 2001; Schaider et al., 2012). In fact, ergot derivatives are normally administered to increase uterine contractions during cesarean section or hemorrhage after delivery (Labriolle et al., 2009).

Combined contraceptive pills, too, are prescribed for treatment of abnormal uterine hemorrhage and might be useful in controlling hemorrhage and expelling the retained tissues after spontaneous abortion (Mehrabian and Abbassi, 2013). Use of these pills after incomplete abortion not only decreases hemorrhage due to retention of pregnancy products, but it also might help expel the retained tissues at the end of the period of taking the pills concomitant with the desquamation of endometrium without any need for surgery. (Gaffield et al., 2009). Since retention of pregnancy products might lead to endometritis, paving the way for uterine adhesions and disturbances during future pregnancies and also since there is no definite technique to treat suspected retained tissues after abortion (Esmaelizadeh et al., 2001), the present study aims to compare the effects of concomitant use of methylergonovine and Low Dose (LD) contraceptive pills, LD pills alone, and methylergonovine pills alone on hemorrhage due to retention of pregnancy products after abortion during the first pregnancy trimester.

\section{Materials and Methods}

In the present randomized clinical trial, the subjects consisted of the women referring to the gynecology and obstetrics clinics of Shiraz University of Medical Sciences due to vaginal hemorrhage after becoming pregnant from July to October 2013 (a total of 4 months). Based on the clinical symptoms and signs and ultrasound examination, the subjects were diagnosed with incomplete abortion. Clinical examinations were carried out by a gynecologist/obstetrician and ultrasound examinations were carried out by a radiologist.

The inclusion criteria of the study consisted of 20-35 years of age, gestational age of 14 weeks or less based on a reliable Normal Last Menstruation Period (NLMP), abdominal ultrasound confirmation for retained pregnancy products with a size of less than $5 \mathrm{~cm}$, hemoglobin level of $10 \mathrm{~g} / \mathrm{dL}$ or higher, stable clinical status, and absence of a history of cardiovascular diseases and thrombophlebitis.

On the other hand, the exclusion criteria of the study were a drop in hemoglobin level (9 $\mathrm{g} / \mathrm{dL}$ and lower), allergic reactions to drugs, and lack of interest and motivation to 
continue treatment. Considering an error rate of $5 \%$ and a power of $80 \%$ and using the following formula, a 111-subject sample size was determined for the study:

$n=\frac{2 \phi^{2} k s^{2}}{(\partial)^{2}}$

First, a complete history was taken from all the patients and the subjects with stable vital signs and without a history of any specific medical conditions was informed about the study procedures, treatment process, and potential side effects. The subjects volunteering to take part in the study then signed written informed consents and were enrolled into the study. Afterwards, the subjects were assigned to 3 groups $(n=37)$ using permutation block randomization as follows:

Group 1: Methylergonovine pill (Methergine), $0.25 \mathrm{mg}$ every 8 hours for 1 week (Minoo Pharmaceutical Company, Iran) in conjunction with LD pills (Abureyhan Pharmaceutical Company, Iran) once a day for 21 days.

Group 2: Methylergonovine pills (Methergine), $0.25 \mathrm{mg}$ every 8 hours for 1 week.

Group 3: LD pills, once a day for 21 days.

A Pictorial Blood loss Assessment Chat (PBAC) was used to evaluate the severity of hemorrhage, in which the values registered by the subjects themselves were used.

Table 1 shows the scheme introduced by Higham in 1990. The scoring system is based on the number of spots on the pads that are used daily and the severity of their dirtiness as well as the number and sizes of the expelled blood clots. The sensitivity and specificity of this scoring system was $86 \%$ and $89 \%$, respectively (Chen and Giudice,1998; Kha and Chien, 2001).
Table is 2-dimensinal; the horizontal axis shows the number of days with bleeding and the vertical axis shows the number of pads contaminated with blood through three scores of mild, moderate, and severe. After the subjects changed the pads every day, they marked the box on the table with respect to the severity of contamination of pads with blood on the corresponding day. The pads were the same shape and size (the standard confirmed by the Iranian Ministry of Health), so that the subjects could mark the severity of hemorrhage precisely. Scores of 1,5 , and 20 were allocated to mild, medium, and severe contamination of pads with blood, respectively. Additionally, scores of 1 and 5 were allocated to the expulsion of small and large blood clots, respectively. At the end of the bleeding period, each mark was multiplied by its score and the acquired values were added up and a total score was achieved. A score of 100 or higher during a 7-day period indicated bleeding of more than $80 \mathrm{~mL}$. At the end of the intervention, the subjects were required to complete the forms. The hemoglobin levels were once again determined and abdominal ultrasound examination was once again carried out to confirm completion of abortion.

After all, the data were entered into the SPSS statistical software, v. 16 and analyzed using descriptive statistical methods, paired and independent t-test, one-way ANOVA, multiple comparisons (with Tukey and Dunnett's tests), chi-square test, and nonparametric tests. $\mathrm{P}<0.05$ was considered as statistically significant.

\section{Ethical considerations}

The protocol of the study was approved by the Ethics Committee of Shiraz University of Medical Sciences under the code of CT6599-92 and the study was registered at Iranian Clinical Trials' website under the 
code of IRCT2013070213845n1. All the consent forms were filled out at the beginning of the study along with the participants' rights.

\section{Results and Discussion}

The present study was carried out on 111 women with a complaint of hemorrhage resulting from abortion, who had referred to the gynecology and obstetrics clinics of Shiraz University of Medical Sciences. The minimum and maximum ages of the subjects were 20 and 45 years, respectively, with no significant differences among the three groups $(\mathrm{P}=0.827)$. Yet, the highest frequency was related to the 25-30 year age group (51.4\%). In addition, no significant differences were found among the three groups regarding education level $(\mathrm{P}=0.966)$, number of pregnancies $(\mathrm{P}=0.861)$, number of abortions $(\mathrm{P}=0.622)$, number of children $(\mathrm{P}=0.860)$, mean gestational age $(\mathrm{P}=0.177)$, hemoglobin levels before the intervention $(\mathrm{P}=0.718)$, and hemoglobin levels after the intervention $(\mathrm{P}=0.732)$. The mean size of the retained tissue after abortion was less than $22 \mathrm{~mm}$ in all the three groups, without any significant differences $(\mathrm{P}=0.645)$.

The results of evaluation of the mean of number of days of hemorrhage and the severity or volume of hemorrhage from the beginning to the end of the intervention showed significant differences among the three groups concerning the number of bleeding days. Based on the results of post hoc Bonferroni tests, significant differences were observed between the methergine-LD and methergine groups $(\mathrm{P}<0.001)$ and between the methergine-LD and LD groups $(\mathrm{P}<0.001)$; however, no significant differences were observed between the methergine and LD groups $(\mathrm{P} \approx 1)$ (Table 2$)$. Thus, use of methergine and LD pills alone resulted in a more significant decrease in the number of bleeding days compared to the concomitant use of these pills.

In addition, the results revealed a significant difference among the three groups with respect to the hemorrhage volume. Due to the inequality of variances, Dunnett's $t_{3}$ post hoc tests were used, which showed no significant differences between the methergine-LD and methergine groups $(\mathrm{P}=0.066)$. However, significant differences were observed between the methergine-LD and LD groups $(\mathrm{P}<0.001)$ as well as between the methergine and LD groups $(\mathrm{P}=0.040) \quad$ (Table 2). Furthermore, the results of chi-square test demonstrated no significant differences among the three study groups regarding the success of complete expulsion of the retained pregnancy products at the end of the intervention $\quad(\mathrm{P}=0.331) \quad$ (Table 3$)$. In addition, no side effects of the medications used were observed in the three study groups.

Abortions during the first pregnancy trimester are one of the most common complaints of the patients referring to gynecology/obstetric clinics, with complications such as retention of pregnancy products and vaginal hemorrhage. Up to now, a large number of studies have been conducted to identify a low-risk and less aggressive treatment modality for treatment of abortion; however, a limited number of medications are available that are both effective and low-risk (Sakhavat et al., 2004). The present study aimed to compare the effects of simultaneous use of methylergonovine (Methergine) and LD combined contraceptive pills and consumption of methylergonovine and LD pills alone on hemorrhage due to the retention of pregnancy products subsequent to abortion during the first trimester of pregnancy. The 
results showed that methylergonovine pills and LD pills alone were more effective in decreasing the number of bleeding days compared to the simultaneous use of these two medications.

In the present study, the retained tissues were completely expelled after completion of the intervention in all the three groups.

The results of a study by Sakhavat et al., (2004) on the effects of methylergonovine maleate on incomplete abortion also showed the effectiveness of the medication. In that study, methylergonovine was effective in completely expelling the pregnancy products in 97 out of the 100 patients, which is consistent with the results of the current study (Sakhavat et al., 2004).

In addition, in a study by Liabsuetraku et al., (2007), preventive use of ergot alkaloids during the third stage of labor resulted in a decrease in the amount of blood loss after delivery (Liabsuetrakul et al., 2007), which is in agreement with the results of the present study in terms of the efficacy of ergot derivatives in decreasing hemorrhage. Methergine decreases hemorrhage by increasing the uterine tonicity and contracting the blood vessels. It also increases the power and number of uterine contractions due to its sympatholytic and oxytocic effects. Therefore, it is used in prevention and treatment of hemorrhage due to uterine atonia after delivery and incomplete abortion (Labriolle et al., 2009; Butwick et al., 2014). Similar to ergot alkaloids, methylergonovine, too, contracts blood vessels by stimulating serotonin and $\alpha$-adrenergic receptors and inhibiting the release of endothelium-derived relaxing factor. The oxytocic affects of methylergonovine are stronger than its vascular effects. It increases the tonicity of the uterus and therefore retards the circulatory flow of the uterus, decreasing hemorrhage (Schaider et al., 2012)

The estrogen components of LD pill, too, stabilize the uterine mucosa and prevent hemorrhage and its irregular desquamation. Hence, using these pills after incomplete abortion not only decreases hemorrhage due to retention of pregnancy products, but it also may result in expulsion of the retained tissue simultaneous with desquamation of endometrium at the end of the drug application period without any need for a surgical operation (Liabsuetrakul et al., 2007). However, on the contrary to the results of the above-mentioned studies, Tang et al., (2002) carried out a research on the immediate use of combined contraceptive pills and their effect on the amount of blood loss during therapeutic abortion and showed that immediate use of LD pills had no impacts on the duration of hemorrhage (Tang and Ho, 2002). In addition, Martin and Brown (1998) carried out a study on the effects of methotrexate and combined contraceptive pills on hemorrhage patterns after inductive abortion with mifepristone and psariprostaglandin, and demonstrated that none of them had any significant effects on the amount and duration of hemorrhage after therapeutic abortion (Martin and Brown, 1998). Similarly, Verma et al., (2006) carried out a study to compare the effects of sublingual misoprostol and methylergonovine on prevention of hemorrhage after delivery and showed that during the third sage, the mean of blood loss and the need for inclusion of oxytocic agents were the same in the study groups (Verma $e t$ al., 2006). Also, Sang et al., (1994) performed a study on the effect of contraceptive pills on the amount of blood loss in cases of therapeutic abortion and showed that immediate use of combined contraceptive pills had no effects on the rate of complete abortion (Sang et al., 1994). 
The results of the present study were not consistent with those of the studies mentioned below.

Agarwal and Kriplani (2001) evaluated the popularity and effect of oral combined contraceptive pills, including ethinyl estradiol $(30 \mu \mathrm{g})$ and desogestrel $(150 \mu \mathrm{g})$, on treatment of non-functional uterine hemorrhage and reported that combined contraceptive pills significantly decreased the amount and duration of hemorrhage in cases of non-functional uterine hemorrhage. It appears that combined contractive pills, with third-generation progesterone in their chemical structure, were effective in treatment of non-functional uterine hemorrhage (Agarwal and Kriplani, 2001). In the current study, the retained tissues were immediately expelled in the methylergonovine- $\mathrm{LD}$ and $\mathrm{LD}$ groups at the end of the treatment period.

Table.1 Pictorial blood assessment chart

\begin{tabular}{|l|l|}
\hline \multirow{4}{*}{} & \multicolumn{2}{|c|}{ PBAC SCORING } \\
\cline { 2 - 2 } & $1=$ Pad rather wet \\
\cline { 2 - 2 } & $5=$ Pad half-wet \\
\cline { 2 - 2 } & $20=$ Pad completelv wet \\
\hline
\end{tabular}

Table.2 The mean number of days with bleeding and bleeding volume from the beginning to the end of the intervention in the three study groups

\begin{tabular}{|c|c|c|c|c|}
\hline Variable & \multicolumn{3}{|c|}{ Mean \pm SD } & P-value \\
\cline { 2 - 5 } & Methergine-LD & Methergine & LD & \\
\hline $\begin{array}{c}\text { The number } \\
\text { of bleeding } \\
\text { days }\end{array}$ & $7.10 \pm 2.96$ & $4.48 \pm 2.53$ & $4.45 \pm 2.92$ & 0.001 \\
\hline $\begin{array}{c}\text { Volume of } \\
\text { bleeding (mL) }\end{array}$ & $28.48 \pm 13.37$ & $21.8 \pm 13.94$ & $14.16 \pm 8.76$ & 0.001 \\
\hline
\end{tabular}


Table.3 The frequency of complete expulsions of the retained pregnancy products at the end of the intervention in the three study groups

\begin{tabular}{|c|c|c|c|c|}
\hline Group & $\begin{array}{c}\text { Methergine-LD } \\
\mathbf{n}(\%)\end{array}$ & $\begin{array}{c}\text { Methergine } \\
\mathbf{n}(\%)\end{array}$ & $\begin{array}{c}\text { LD } \\
\mathbf{n}(\%)\end{array}$ & P-value \\
\hline $\begin{array}{c}\text { Complete } \\
\text { expulsion of } \\
\text { pregnancy } \\
\text { products }\end{array}$ & $37(100)$ & $35(94.6)$ & $37(100)$ & 0.331 \\
\hline
\end{tabular}

However, in two subjects in the methylergonovine group, the expulsion did not immediately occur after completion of the intervention. Of course, no extra intervention was performed for these two subjects and they were monitored for 1-2 weeks during which expulsion took place. Expulsion of retained tissues might be influenced by various factors, including gestational age and size of the tissue (Baird, 2002). In the study by Sakhavat, $97 \%$ of the patients responded to methylergonovine (injected or injected/oral) and the pregnancy products were completely expelled without curettage (Sakhavat et al., 2004), which is in line with the results of the present study.

Some of the limitations of our study were the short follow-up period and the small sample size. In addition, due to the risk of thrombosis and increase in blood pressure, this procedure was limited to high-risk women.

In conclusion, based on the results of the present study, it appears that combined LD contraceptive pills and methylergonovine pills, each separately, resulted in a decrease in the number of bleeding days, while simultaneous use of these pills was not that advantageous.

In addition, LD pills had more significant effects on decreasing the volume of blood loss compared to consumption of methylergonovine pills and combined use of LD-methylergonovine. Yet, all the subjects completely expelled the pregnancy products without any specific complications. It seems that LD pills can be used in women with retained pregnancy tissues after abortion during the first trimester and without active hemorrhage in case they have no risk factors for the use of combined conceptive pills.

\section{Acknowledgements}

The present article was extracted from the thesis of Ms. Tahere Abdullahi Tehrani (proposal No. 6599) approved and financially supported by the Research Vicechancellor of Shiraz University of Medical Sciences. They are grateful for Ms. A. Keivanshekouh at the Research Improvement Center of Shiraz University of Medical Sciences for improving the use of English in the manuscript.

\section{References}

Agarwal, N., Kriplani, A. 2001. Medical management of dysfunctional uterine bleeding. Int. J. Gynecol. Obstetrics, 75(2): 199-201.

Bair, D.T. 2002. Medical abortion in the first trimester. Best Pract. Res. Clin. Obstet. Gynaecol., 16(2): 221-36. 
Butwick, A.J., Carvalho, B., El-Sayed, Y.Y. 2014. Risk factors for obstetric morbidity in patients with uterine atony undergoing caesarean delivery. Br. J. Anaesth., 113(4): 661-8.

Chen, B., Giudice, L. 1998. Dysfunctional uterine bleeding. Western J. Med., 169(5): 280-4.

Cunningham, F.G., Leveno, K.J., Bloom, S.L. 2010. Williams obstetrics. 23thed. Philadelphia, PA: Wolters Kluwer, Lippincott Williams and Wilkins.

Debby, A., Malinger, G., Harow, E., Golan, A., Glezerman, M. 2006. Transvaginal ultrasound after first-trimester uterine evacuation reduces the incidence of retained products of conception. Ultrasound in obstetrics \& gynecol., 27(1): 61-4.

Esmaelizadeh, S., Aghapour, M. , Bizhani, A. 2001. Expected management of first trimester spontaneous abortion with $12 \mathrm{~mm}$ or less of endometrial line. J. Babol Univ. Med. Sci., (JBUMS), 3(4): 25-8.

Gabbe, S.G., Niebyl, J.R., Galan, H.L., Jauniaux, E.R., Landon, M.B., Simpson, J.L., et al. 2012. Obstetrics : normal and problem pregnancies. 6th ed . Philadelphia: Elsevier Saunders.

Gaffield, M.E., Kapp, N., Ravi, A. 2009. Use of combined oral contraceptives post abortion. Contraception, 80(4): 355-62.

Griebel, C.P., Halvorsen, J., Golemon, T.B., Day, A.A. 2005. Management of spontaneous abortion. Am. Fam. Physician, 72(7): 1243-50.

Jahangir, M., Behrashi, M., Fazel, M.R., Arbabi, M. 2005. Efficacy of vaginal Misoprostol for terminating missed abortion. KAUMS J., (FEYZ ) 9(2): 15.

Kha, K.S., Chien, P.F. 2001. Evaluation of a clinical test. I: assessment of reliability. BJOG: An International $J$.
Obstetrics \& Gynaecol., 108(6): 5627.

Labriolle, A., Genée, O., Heggs, L.M., Fauchier, L. 2009. Acute myocardial infarction following oral methylergometrine intake. Cardiovascular Toxicol., 9(1): 46-8.

Liabsuetrakul, T., Choobun, T., Peeyananjarassri, K., Islam, Q.M. 2007. Prophylactic use of ergot alkaloids in the third stage of labour. Cochrane Database Syst. Rev., 18 (2):CD005456.

Lohr, P., Hayes, J., Gemzell-Danielsson, K. 2008. Surgical versus medical methods for second trimester induced abortion (Review). Cochrane Database of Syst Rev., 23(1): CD006714.

Martin, C.W., Brown, A.H., Baird, D.T. 1998. A pilot study of the effect of methotrexate or combined oral contraceptive on bleeding patterns after induction of abortion with mifepristone and a prostaglandin pessary. Contraception, 58(2): 99-103.

Mehrabian, F., Abbassi, F. 2013. Comparing the effects of low-dose contraceptive pills to control dysfunctional uterine bleeding by oral and vaginal methods. Pak. J. Med. Sci., 29(5): 1208-11.

Sakhavat, L., Baiki, A., Hashwminezhad, M. 2004. Evaluation of results of medical treatment of first trimester incomplete abortion with methyl ergonovine maleate(methergine). J. Shahid Sadoughi University of Medical Sci. Health Services, 12(1): 29-34.

Sang, G.W., Weng, L.J., Shao, Q.X., Du, M.K., Wu, X.Z., Lu, Y.L., et al. 1994. Termination of early pregnancy by two regimens of mifepristone with misoprostol and mifepristone with PG05-a multicentre randomized clinical trial in China. Contraception, 50(6): 501-10. 
Schaider, J.J., Barkin, R.M., Hayden, S.R., Wolfe, R.E., Barkin, A.Z., Philip, Shayne, P. et al. 2012. Rosen \& Barkin's 5-Minute Emergency Medicine Consult.4th ed. PA: Wolters Kluwer.

Tang, O.S., Ho, P.C. Medical abortion in the second trimester(2002). Best Practice and Research: Clin. Obstetrics and Gynaecol., 16(2): pp. 237-246.

Verma, P., Aggarwal, N., Jain, V., Suri, V. 2006. A double-blind randomized controlled trial to compare sublingual misoprostol with methylergometrine for prevention of postpartum hemorrhage. Int. J. Gynecol. Obstetrics, 94 (supple2): S137-S8.

\section{How to cite this article:}

Maasumeh Kaviani, Tahere Abdullahi Tehrani, Sara Azima, Khadijeh Abdali and Nasrin Asadi. 2016. Comparison of the Effects of Simultaneous Use of Methylergonovine and Combined Low-dose (LD) Contraceptive Pills on Hemorrhage Due to Retained Pregnancy Products after Abortion. Int.J.Curr.Microbiol.App.Sci. 5(11): 499-507. doi: http://dx.doi.org/10.20546/ijcmas.2016.511.058 